\title{
Caracterización de las aguas residuales y la demanda bioquímica de oxígeno
}

\section{RESUMEN}

El agua es la sustancia más importante para los seres vivos, después del oxígeno. Es parte constituyente de la mayoría de los animales y los vegetales y está presente en cantidad de minerales (Raffo Lecca, Tratado del Agua y la Legislación Peruana, 2013).

La Demanda Bioquímica de Oxígeno (DBO) es uno de los indicadores más importantes en la medición de la contaminación en aguas residuales, como también en el control del agua potable.

Palabras clave: agua superficial, agua subterránea, contaminantes orgánicos y demanda bioquímica de oxígeno

Characterisation OF Waste Water and BIOCHEMICAL OXYGEN DEMAND

\section{ABSTRACT}

Water is the most important substance for human beings, after oxygen. Is a constituent of most animals and plants and is present in amount of minerals (Raffo Lecca, Treated Water And Peruvian Law, 2013).

The BOD is one of the most important indicators in measuring pollution in wastewater, as well as in drinking water control.

Keywords: surface water, groundwater, organic pollutants and biochemical oxygen demand

\section{GENERALIDADES}

La investigación hidrológica es útil en cuanto nos permite entender mejor el mundo en el que vivimos, y también proporciona conocimientos para la ingeniería ambiental, política y planificación.

La Ecología con el estudio de la eutrofización, específica el aporte más o menos masivo de nutrientes inorgánicos en un ecosistema acuático.

\subsection{Agua superficial y agua subterránea}

El agua subterránea constituye una fracción importante de la masa de agua presente en los continentes. Esta se aloja en los acuíferos bajo la superficie de la Tierra. El volumen del agua subterránea es mucho mayor que la masa de agua retenida en lagos o circulante [1].

El uso de las aguas subterráneas tiene como inconveniente, el de proporcionar aguas excesivamente duras, debido a que los constituyentes que causan la dureza son los lavados de los cuerpos mineralizados (Dpto. de Sanidad del Estado de NY, 2012).

La capa que contiene agua subterránea se denomina acuífero; existiendo dos tipos de acuíferos: el freático y el artesiano. El primero se denomina cuando la capa superficial se encuentra a presión atmosférica o normal. El artesiano es el acuífero que se encuentra a una presión mayor que la atmosférica (Raffo Lecca, Tratado del Agua y Legislación Peruana, 2013).

Al acuífero se llega a través de pozos y galerías. El pozo, desaloja la tierra que rodea al agua, permitiendo que en el hoyo, se acumule grandes cantidades de agua, para ser aprovechada por el ser humano. Algunos pozos se hacen sobre un acuífero en el que el agua circula desde un punto más alto a un punto más bajo. Si el punto más alto está lo suficientemente elevado y cerca, al perforar el pozo el agua asciende hasta el nivel de base del punto alto. A este se le llama pozo artesiano, y en él el nivel piezométrico está por encima de la superficie de la tierra.

\footnotetext{
Ingeniero Industrial. Profesor Asociado del Departamento Académico de Ingeniería de Sistemas e Informática, UNMSM. E-mail: eraffolecca@yahoo.es

** Magíster en Informática. Profesor Principal del Departamento Académico de Sistemas e Informática, UNMSM. E-mail: edgar.ruiz@industrial.unmsm.pe
} 
Figura 1. Relaciones entre aguas superficiales y subterráneas.

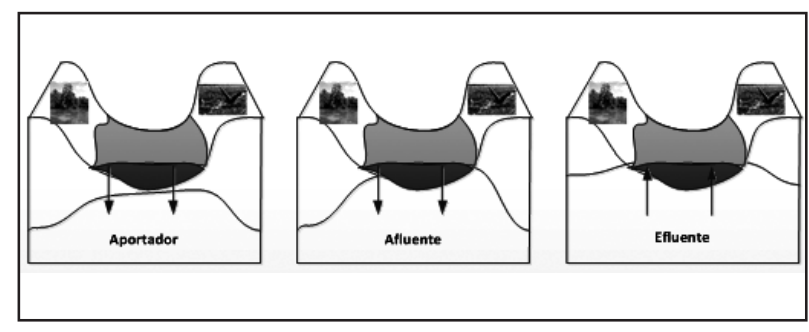

Fuente: Elaboración propia.

En ocasiones el nivel freático del acuífero está tan elevado que sale a la superficie; en realidad lo que pasa es que la presión del nivel piezométrico hace surgir el agua, denominándose manantiales; y cuando las aguas de este manantial surgen calientes, se tienen las aguas termales.

Todos los acuíferos tienen dos características fundamentales: capacidad de almacenar agua subterránea y capacidad de permitir el flujo del agua subterránea.

La relación entre el agua superficial con un acuífero es importante en la caracterización de sistemas de agua subterránea. Se distinguen entre:

- Arroyos y ríos de los que son aportadores a un acuífero como fuentes significativas de su recarga total.

- Arroyos y ríos que actúan como afluentes a un acuífero, por recarga.

- Arroyos y ríos que a su vez dependen de la descarga de un acuífero para mantener su flujo en estiaje; actuando el acuífero como efluente.

Al respecto ver la figura 1.

\subsection{Humedales y bofedales}

Los humedales son zonas en las que el agua es el principal factor que controla el medio y la vida vegetal y animal relacionada con él. Se dan en los lugares donde la capa freática se halla en o cerca de la superficie de la tierra o donde la tierra está cubierta de agua poco profunda.

Según la Convención sobre los Humedales de Importancia Internacional: "Son extensiones de marismas, pantanos y turberas, o superficies cubiertas de agua, sean éstas de régimen natural o artificial, permanentes o temporales, estancadas o corrientes, dulces, salobres o saladas, incluidas las extensiones de agua marina cuya profundidad en marea baja no exceda de seis metros".

La Convención sobre los Humedales, llamada la Convención de Ramsar (Ramsar, Irán, 1971), es un tratado intergubernamental que sirve de marco para la acción nacional y la cooperación internacional en pro de la conservación y el uso racional de los humedales y sus recursos (La Convención de Ramsar).

La filosofía de Ramsar gira en torno al concepto de "uso racional". El uso racional de los humedales se define como "el mantenimiento de sus características ecológicas, logrado mediante la implementación de enfoques por ecosistemas, dentro del contexto del desarrollo sostenible".

Figura 2. Humedales.

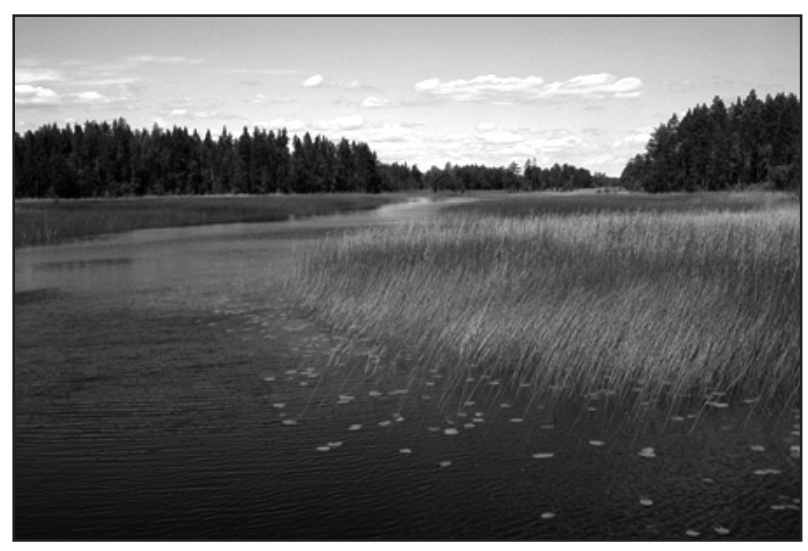

Fuente: http://www.ramsar.org

Los humedales son ecosistemas de gran importancia por los procesos hidrológicos y ecológicos que en ellos ocurren y la diversidad biológica que sustentan (ver la figura 2).

Entre los procesos hidrológicos que se desarrollan en los humedales se encuentran la recarga de acuíferos, cuando el agua acumulada en el humedal desciende hasta las napas subterráneas. Las funciones ecológicas que desarrollan los humedales favorecen la mitigación de las inundaciones y de la erosión costera. Además, a través de la retención, transformación y/o remoción de sedimentos, nutrientes y contaminantes juegan un papel fundamental en los ciclos de la materia y en la calidad de las aguas.

Se denomina bofedal al humedal de altura y se considera una pradera poco extensa con permanente humedad. Los vegetales o plantas que habitan el bofedal reciben el nombre de 
vegetales hidronímicos. Los bofedales se forman en zonas como las de las mesetas andinas ubicadas sobre los 3800 metros de altura, en donde las planicies almacenan aguas provenientes de precipitaciones pluviales, deshielo de glaciares y principalmente afloramientos superficiales de aguas subterráneas.

Las interacciones de un humedal con el suelo, agua, fauna y flora, hacen posible que el humedal desempeñe muchas funciones vitales, como por ejemplo: almacenamiento de agua, mitigación de inundaciones, recarga de acuíferos, descarga de acuíferos, purificación de las aguas mediante la retención de nutrientes, sedimentos y contaminantes, entre otras funciones.

\subsection{Eutrofización}

En ecología el término eutrofización está referido al enriquecimiento en nutrientes de un ecosistema. El uso más extendido se refiere específicamente al aporte más o menos masivo de nutrientes inorgánicos en un ecosistema acuático. Eutrofizado es aquel ecosistema o ambiente caracterizado por una abundancia anormalmente alta de nutrientes [5].

La eutrofización produce de manera general un aumento de la biomasa y un empobrecimiento de la diversidad. En ecosistemas acuáticos, con la eutrofización empiezan a proliferar algas unicelulares, en general algas verdes (ver la figura 3).

En un cuerpo de agua cerrado, como una laguna, el proceso de eutrofización puede terminar por convertir al cuerpo de agua en tierra firme. Esto debido a los nutrientes que ingresan masivamente al cuerpo, generando una gran biomasa de organismos de vida generalmente efímera que al morir se acumulan sobre el fondo y no son totalmente consumidos por organismos degradadores (especialmente bacterias).

Según Ramalho (2003): "La eutrofización es el proceso natural de envejecimiento de los lagos. Progresa aún sin tener la ayuda del hombre". La contaminación, acelera el envejecimiento natural y acorta considerablemente la vida del cuerpo receptor.

Las principales causas de la eutrofización son:

- El efecto de las aguas residuales ricas en fósforo y nitrógeno.

- La contaminación atmosférica por óxidos de azufre y nitrógeno que reaccionan con el agua atmosférica para formar iones de sulfato y nitrato.

- La contaminación agropecuaria por los fertilizantes o excrementos.
- La contaminación forestal por abandono en los ríos de residuos forestales.

Figura 3. Eutrofización.

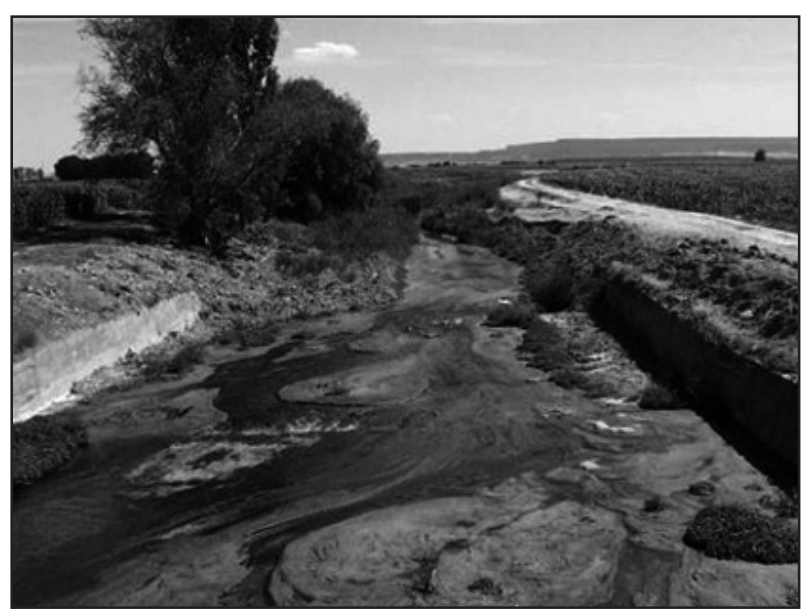

Fuente: Ecología verde

\section{CLASIFICACIÓN DE LOS CONTAMINANTES DE LAS AGUAS RESIDUALES}

Desde su origen, los suministros de agua se clasifican en tres categorías: aguas superficiales, aguas subterráneas y aguas meteorológicas (Ramalho, 2003).

Desde el punto de vista del tratamiento de las aguas residuales, éstas pueden ser las aguas utilizadas por el hombre para cubrir sus necesidades, o las aguas que se han emitido como residuos líquidos después de su utilización.

El agua pura no se encuentra en forma natural. Cuando el agua entra en contacto con el aire, suelo, o el hombre, adquiere impurezas y se contamina; lo que ocasiona enfermedades y perjuicios al ser humano (Raffo Lecca, 2013).

El agua que ha sido retirada y retornada, estará contaminada de un modo u otro. El agua de retorno agrícola contiene pesticidas, fertilizantes y sales; el retorno municipal arrastra deshechos humanos, farmacéuticos y detergentes; las centrales eléctricas descargan agua que está a temperaturas elevadas. De todos ellos, el sector industrial contribuye con contaminantes químicos y de residuos orgánicos (Masters, 2008).

\subsection{Contaminantes químicos y biológicos}

Los contaminantes del agua en función a la calidad - las características del agua se clasifican en físicos, químicos y biológicos. Estas impurezas por 
el lado de las características químicas deben su origen a contaminantes orgánicos e inorgánicos.

Los contaminantes orgánicos dan como resultado la disminución del oxígeno, producto de la degradación biológica de los compuestos. En el caso de los contaminantes inorgánicos, el resultado es su posible efecto tóxico.

La degradación biológica de sustancias orgánicas produce ácidos grasos, carbohidratos, aminoácidos e hidrocarburos; y las sustancias inorgánicas en el caso de metales tóxicos, de material particulado como arcillas y sedimentos; y de microorganismos como bacterias y protozoos. (Ver la tabla 1 contaminantes químicos y biológicos).

Tabla 1. Contaminantes químicos y biológicos

\begin{tabular}{|c|c|c|}
\hline \multirow{5}{*}{ Químicos } & \multirow{4}{*}{$\begin{array}{l}\text { Químicos } \\
\text { corrientes }\end{array}$} & $\begin{array}{l}\text { Metales tóxicos, como } \\
\text { el hierro, manganeso, } \\
\text { plomo, mercurio, } \\
\text { arsénico, cadmio, cobre, } \\
\text { entre otros. }\end{array}$ \\
\hline & & $\begin{array}{l}\text { Compuestos } \\
\text { nitrogenados, como } \\
\text { amoniaco, nitrato y } \\
\text { nitrito, carbonato o } \\
\text { bicarbonato de calcio y } \\
\text { magnesio. }\end{array}$ \\
\hline & & $\begin{array}{l}\text { Aniones, como fluoruro, } \\
\text { sulfato y silicatos. }\end{array}$ \\
\hline & & Sustancias orgánicas. \\
\hline & $\begin{array}{c}\text { Carácter } \\
\text { antropogénica }\end{array}$ & Cianuros y fenoles. \\
\hline \multirow{4}{*}{ Biológicos } & Bacteria & $\begin{array}{l}\text { Salmonella typhi, } \\
\text { leptospira, escherichia } \\
\text { coli, yersinia, vibrio } \\
\text { cholerae, Shigella. }\end{array}$ \\
\hline & Virus & Adenovirus, rotavirus. \\
\hline & Hongos & $\begin{array}{l}\text { Aspergillus fumigatus, } \\
\text { candida albanicans. }\end{array}$ \\
\hline & Helmintos & $\begin{array}{l}\text { Ascaris lumbricoides, } \\
\text { fasciola hepatica, Taenia } \\
\text { saginata, trichuris } \\
\text { trichura. }\end{array}$ \\
\hline
\end{tabular}

Fuente: Elaboración propia.
Se denomina metal tóxico o pesado, a cualquier elemento químico metálico que tenga una relativa alta densidad y sea tóxico o venenoso en concentraciones bajas. En la tabla periódica, se ubican por tener un peso específico superior a $5 \mathrm{~g} / \mathrm{cm}^{3}$ o tienen un número atómico por encima de 20, sin considerar a los metales alcalinos y elementos alcalinotérreos (Breckle, 1991; Tiller, 1989).

Los metales tóxicos son constituyentes naturales de la corteza de tierra; no pueden ser degradados o ser destruidos. Todos los suelos poseen metales pesados como consecuencia de los procesos geológicos y edafogenéticos. Los metales pesados son bioacumulables, porque alcanzan concentraciones más altas comparadas con la de otros metales que normalmente se acumulan en el medio ambiente. Los metales pesados de más importancia son el mercurio $(\mathrm{Hg})$, el plomo $(\mathrm{Pb})$, el cadmio (Cd) y el arsénico (As).

A través de la cadena trófica, los metales tóxicos se van acumulando en los tejidos y músculos de los seres vivos, debilitando las defensas y provocando una serie de enfermedades; llegando en los seres humanos a provocar lesiones graves, inclusive la muerte.

\subsection{Contaminación antropogénica}

La contaminación en el agua, vista desde la intervención humana se clasifica en natural y antropogénica.

La contaminación natural se debe a la presencia de determinadas sustancias en el agua sin que intervenga la acción humana, teniendo orígenes muy diversos.

La contaminación antropogénica o humana, es consecuencia de las actividades humanas, como son las actividades mineras, agropecuarias, industriales, artesanales y domésticas. Por su naturaleza son las más graves por la gran variedad de contaminantes que genera. Aquí se encuentran los fenoles, cianuros, cromo y detergentes.

El fenol es el ingrediente más importante en la preparación de resinas sintéticas, colorantes, medicamentos, plaguicidas, curtientes sintéticos, sustancias aromáticas, aceites lubricantes y solventes.

El cianuro es una sustancia química potencialmente letal, que actúa rápidamente y puede existir de varias formas. Puede ser un gas incoloro o estar en forma de cristales. En las operaciones mineras, el proceso de lixiviación (separación de metales) con cianuro, produce daños ambientales a corto y largo 
plazo. La filtración de esta sustancia química en las napas freáticas y los perjuicios que ocasiona a la salud, son ejemplos de estos daños.

\subsection{Medida de concentración en Aguas Residuales (AR)}

Cerca del $75 \%$ de los sólidos en suspensión y del $40 \%$ de los sólidos filtrables de un agua residual de concentración media son de naturaleza orgánica (Metcalf \& Eddy, 1985). Son sólidos que provienen de los reinos animal y vegetal, así como de las actividades humanas relacionadas con la síntesis de compuestos orgánicos.

Para poder evaluar el daño que pueden llegar a producir las aguas residuales, se emplean diversas técnicas.

Según Ramalho (2003), los métodos analíticos para contaminantes orgánicos se clasifican en dos grupos:

- De evaluación de la demanda de oxígeno.

- De los parámetros de contenido en carbono.

En el primer grupo, se encuentra la demanda teórica de oxígeno (DT $\mathrm{O}$ ), la demanda química de oxígeno (DQO), la demanda bioquímica de oxígeno (DBO) y la demanda total de oxígeno (DTO). Estas técnicas determinan la cantidad de materia orgánica putrescibles que se encuentran presentes en el agua contaminada.

Para las aguas negras, que tienen una composición más o menos constante, se emplea la cantidad de carbono presente en las mismas, ya sea directamente, midiendo el carbono orgánico teórico $\left(\mathrm{COT}_{\mathrm{e}}\right)$ o el carbono orgánico total; éste último es conocido como COT.

La demanda teórica de oxígeno o $\mathrm{DT}_{\mathrm{e}} \mathrm{O}$, es la cuantificación estequiométrica del oxígeno requerido para oxidar completamente un determinado compuesto a partir de su fórmula química. $\mathrm{DT}_{\mathrm{e}} \mathrm{O}$ es la cantidad teórica de oxígeno requerido para oxidar la fracción orgánica de un desecho hasta dióxido de carbono y agua.

Para una solución de $500 \mathrm{mg} / \mathrm{l}$ de lactosa, la ecuación de oxidación completa es:

$$
\mathrm{C}_{6} \mathrm{H}_{12} \mathrm{O}_{6}+6 \mathrm{O}_{2} \rightarrow 6 \mathrm{CO}_{2}+6 \mathrm{H}_{2} \mathrm{O}
$$

El valor de $\mathrm{DT}_{\mathrm{e}} \mathrm{O}$, se determina cuando $180 \mathrm{~g}$ de lactosa consumen $6(32)=192 \mathrm{~g}$ de oxígeno; luego en una solución de $500 \mathrm{mg} / \mathrm{l}$ se tiene:

$\underline{192} \times 500=533.33 \mathrm{mg} / \mathrm{l}$

180
La demanda química de oxígeno (DQO) indica el contenido de materia orgánica del cuerpo de agua; se usa para medir el oxígeno equivalente a la materia orgánica oxidable mediante un agente químico oxidante, generalmente el dicromato de potasio es el agente oxidante por su característica de oxidar casi todos los compuestos orgánicos (con excepción de los ácidos grasos de bajo peso molecular), en un medio ácido y a alta temperatura. Es muy usado para medir la materia orgánica en las aguas residuales urbanas e industriales.

$\mathrm{C}_{\mathrm{n}} \mathrm{H}_{\mathrm{a}} \mathrm{O}_{\mathrm{b}}+6 \mathrm{CrO}_{7}^{-2}+8 \mathrm{cH}^{+} \rightarrow \mathrm{nCO}_{2}+[(\mathrm{a}+8 \mathrm{c}) / 2] \mathrm{H}_{2} \mathrm{O}$

$+2 \mathrm{cCr}^{+3}$

Donde:

$c=\frac{2 n}{3}+\frac{a}{6}-b / 3$

Esta técnica es muy útil cuando las aguas residuales llevan sustancias tóxicas, toda vez que puede ser la única manera de determinar la carga orgánica. La oxidación química es más rápida que la oxidación biológica.

\section{DEMANDA BIOQUÍMICA DE OXÍGENO}

Las aguas superficiales son, altamente susceptibles a la contaminación; siendo el vertedero tradicional a lo largo de toda la historia de la industria y las poblaciones. En el caso de los contaminantes residuos que demandan oxígeno, afectan a las corrientes de agua como a las aguas estancadas.

La materia orgánica requiere oxígeno para ser degradada en un curso de agua. El alto contenido orgánico favorece el crecimiento de bacterias y hongos. El oxígeno utilizado para la oxidación de la materia orgánica, consume el oxígeno utilizado para el desarrollo de la fauna y flora acuática. Entre los efectos al ecosistema, se encuentra el cambio en la calidad del agua, y la posible elevación del $\mathrm{pH}$, provocando la desaparición de peces y plantas.

\subsection{Indicador de la contaminación}

A finales de la centuria 19, Dupré encontró que existía una relación entre la concentración del oxígeno disuelto en el agua (OD) y su grado de contaminación.

A mayor cantidad de materia orgánica contenida en una muestra de agua, más cantidad de oxígeno necesitan los microorganismos para oxidarla o degradarla. 
La actividad biológica es provocada por los microorganismos en condiciones aeróbicas, dando como consecuencia que la materia orgánica pierda sus propiedades contaminantes. Aquí existe el intercambio del oxígeno del aire con el agua.

La cantidad de oxígeno que necesitan los microorganismos para oxidar residuos orgánicos de modo aerobio se denomina Demanda Bioquímica de Oxígeno.

La Demanda Bioquímica de Oxígeno (DBO) se usa como una medida de la cantidad de oxígeno requerido para oxidación de la materia orgánica biodegradable, presente en la muestra de agua, como resultado de la acción de oxidación aerobia (Ramalho, 2003).

En condiciones normales de laboratorio, la DBO se determina a una temperatura de $20^{\circ} \mathrm{C}$ en un tiempo de 5 días, siendo expresado en $\mathrm{mg} / \mathrm{l} \mathrm{O}_{2} \mathrm{y}$ es conocido como $\mathrm{DBO}_{5}$. Este procedimiento fue adoptado en 1936 por la Asociación Americana de Salud Pública, y desde entonces ha permanecido como un indicador de la contaminación.

La DBO es uno de los indicadores más importantes en la medición de la contaminación en aguas residuales $(A R)$, como también en el control del agua potable.

Figura 4. Concentración de oxígeno residual.

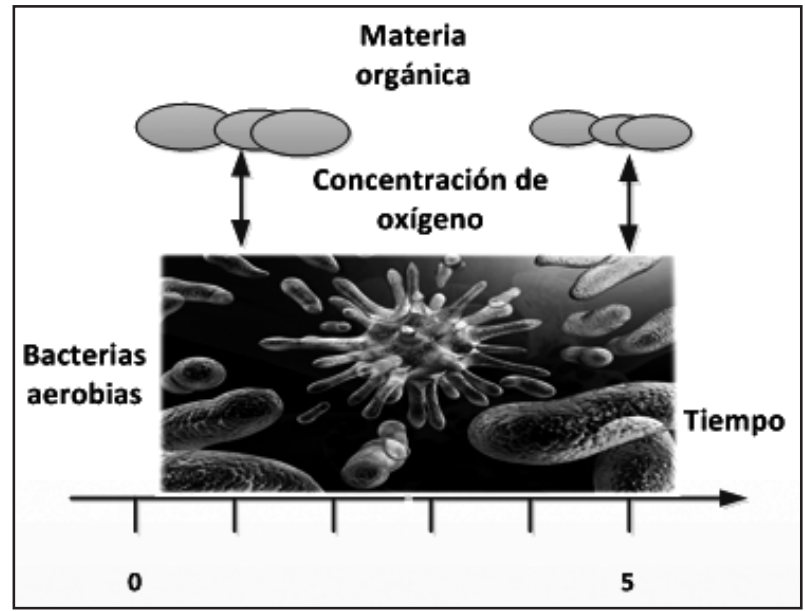

Fuente: Elaboración propia.

Las bacterias aerobias requieren de oxígeno para consumir la materia orgánica degradable presente en las AR. La cantidad consumida de oxígeno, se mide en la diferencia entre el oxígeno al principio y final de la prueba (ver figura 4).
Entre otras aplicaciones para la DBO, se mencionan:

- Medición de la calidad en las aguas superficiales y aguas residuales.

- Establecimiento de Límites Máximos Permisibles (LMP).

- Evaluación de Plantas de Tratamiento de Aguas Residuales o PTAR.

- Diseño de unidades de tratamiento biológicos.

La DBO de cinco días, o $\mathrm{DBO}_{5}$ es la cantidad total de oxígeno consumida por los microorganismos durante los primeros cinco días de biodegradación. En su forma más simple, la prueba $\mathrm{DBO}_{5}$, es poner una muestra de residuo en una botella cerrada y medir la concentración de oxígeno disuelto (OD) en la muestra al principio de la prueba y al cabo de cinco días; la diferencia de OD dividida por el volumen de desperdicio $(\mathrm{P})$ es $\mathrm{DBO}_{5}$ :

$$
D B O_{\text {final }}=\frac{O D_{\text {inicio }}-O D_{\text {final }}}{P}
$$

\subsection{Modelo matemático}

El modelo de la DBO fue propuesto por StreeterPhelps, basándose en la ley empírica de Thierault. Este modelo es una ecuación diferencial de primer orden (ODE) que parte del supuesto que la velocidad de oxidación bioquímica de la materia orgánica es directamente proporcional a la cantidad de materia orgánica biodegradable presente (Romero, 2005):

$$
\frac{d L_{t}}{d t}=-k_{1} L
$$

Donde:

$\mathrm{L}_{\mathrm{t}}=$ Es la DBO remanente en el agua en el tiempo .

$\mathrm{k}_{1}=$ Constante cinética $(\mathrm{mg} / \mathrm{l})$.

$\mathrm{L}=\mathrm{DBO}$ remanente en .

La solución a la ODE es:

$L=L e^{-k_{1} t}$, equivalente $a$ :

$$
L t=L \times 10^{-k t}, K=\frac{k_{1}}{\ln (10)}
$$

La DBO en cualquier tiempo, viene dada como la diferencia entre el valor al principio y el valor del tiempo (ver la figura 5):

$$
y=L-L_{t}=L\left(1-10^{-k t}\right)
$$


Figura 5. DBO en el tiempo t.

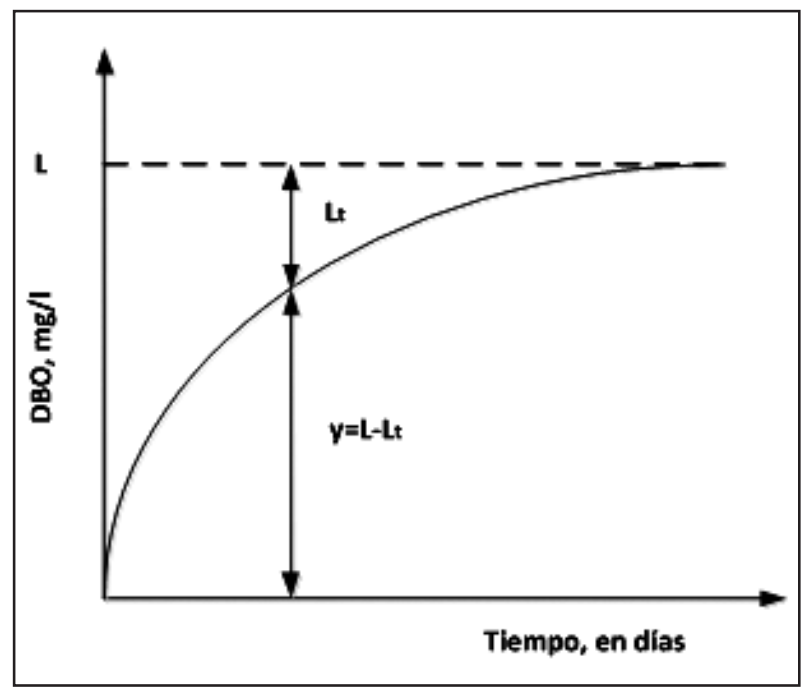

Fuente: Elaboración propia.

La relación entre la $\mathrm{DBO}_{5}$ y la $\mathrm{DQO}$ indica la importancia de los vertidos dentro de las aguas residuales y su posibilidad de biodegradación. El ratio $\mathrm{DBO}_{5} / \mathrm{DQO}$ si se encuentra en el rango el agua es poco biodegradable; en , el agua es biodegradable; y a valores mayores indica que el agua es altamente biodegradable.

La determinación de la constante, para una temperatura diferente a $20^{\circ} \mathrm{C}$, es de acuerdo a la ecuación de Arrhenius:

$$
\mathrm{K}_{\mathrm{T}}=\mathrm{K}_{20} \Theta^{\mathrm{T}-20}
$$

Donde:

$\mathrm{K}_{\mathrm{T}}=$ Constante para una temperatura $\mathrm{T}$

$\mathrm{K}_{20}=$ Constante para una temperatura $\mathrm{T}=20^{\circ} \mathrm{C}$

$\Theta=1.056$ para $T$ entre 20 y $30,1.135$ para $T$ entre 4 y 20

(Ver la Figura 6).

>Arrhenius $(0.1014,29.5020)$

\subsection{Cálculo de la constante cinética}

Existen una variedad de métodos para determinar el valor de la constante cinética y , destacando: mínimos cuadrados, Thomas y Moore. El software MATLAB $\circledast$ ha sido utilizado para los cálculos.

El método de mínimos cuadrados, hace uso de la Ecuación Diferencial Ordinaria (ODE) de StreeterPhelps y obtiene las constantes de la línea de regresión haciendo uso de la derivada numérica.
Figura 6. DBO a temperaturas diferentes de $20^{\circ} \mathrm{C}$.

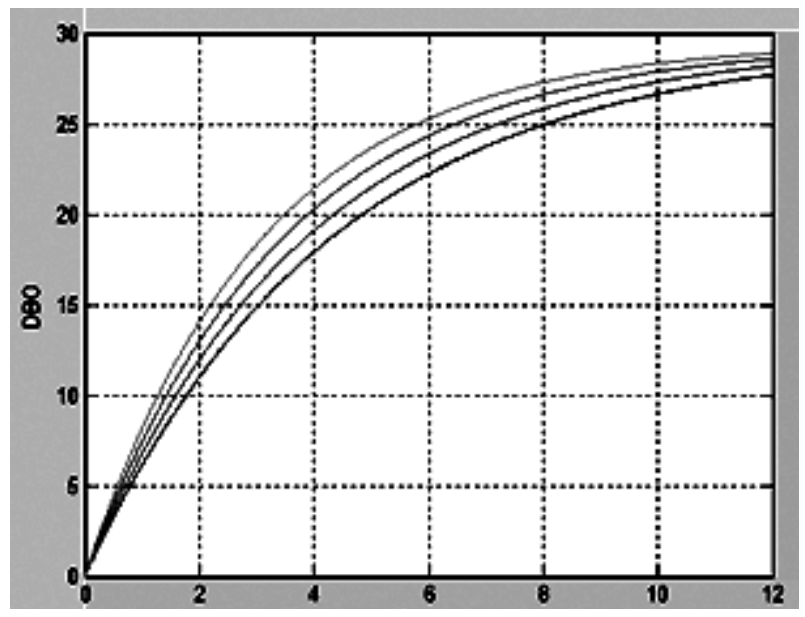

Fuente: Elaboración propia.

Tabla 2. Ensayos DBO

\begin{tabular}{|c|c|}
\hline $\mathrm{T}$ (días) & $\mathrm{Y}(\mathrm{mg} / \mathrm{l}$ de $\mathrm{DBO})$ \\
\hline 2 & 11 \\
\hline 4 & 18 \\
\hline 6 & 22 \\
\hline 8 & 24 \\
\hline 10 & 26 \\
\hline
\end{tabular}

Fuente: Romero (2005).

Usando los datos de Romero (2005) que aparecen en la tabla 3, se encuentra:

$>y=\left[\begin{array}{lllll}11 & 18 & 22 & 24 & 26\end{array}\right]$;

$>\mathrm{t}=2: 2: 10$

$>>[a, b, k 1, k, L]=\operatorname{minimos}(t, y)$;

$\mathrm{a}=7.5285$

$b=-0.2715$

$\mathrm{k} 1=0.2715$

$\mathrm{k}=0.1179$

$\mathrm{L}=27.7273$

El método de Thomas, construye la ecuación , donde:

$$
z=\left(\frac{t}{y}\right)^{1 / 3}, a=(K L)^{-1 / 3}, b=\left(\frac{K^{2 / 3}}{6 L^{1 / 3}}\right)
$$


Tabla 3. Ensayos DBO

\begin{tabular}{|c|c|}
\hline $\mathbf{T}$ (días) & $\mathbf{Y}$ (mg/l de DBO) \\
\hline 1 & 30 \\
\hline 2 & 53 \\
\hline 3 & 69 \\
\hline 7 & 81 \\
\hline 8 & 90 \\
\hline
\end{tabular}

Fuente: Romero (2005).

Usando los datos de la tabla 3, se encuentra:

$>\mathrm{t}=\left[\begin{array}{lllll}1 & 2 & 3 & 7 & 8\end{array}\right]$;

$>>y=\left[\begin{array}{lllll}30 & 53 & 69 & 81 & 90\end{array}\right] ;$

$>$ > $\mathrm{a}, \mathrm{b}, \mathrm{k} 1, \mathrm{k}, \mathrm{L}]=$ Thomas $(\mathrm{t}, \mathrm{y})$;

$a=0.2989$

$b=0.0192$

$\mathrm{k} 1=0.3850$

$\mathrm{k}=0.1672$

$\mathrm{L}=97.2678$

Usando los datos de Ramalho (2003) que aparecen en la tabla 4, se encuentran los valores usando el programa MATLAB Moore:

$>\mathrm{t}=1: 7$;

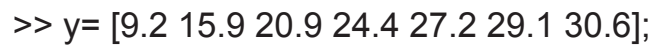

$>[k 1, k, L]=$ Moore $(t, y, 7)$;

$\mathrm{k}=0.1341$

$\mathrm{L}=34.5465$

La teoría que acompaña a cada método esta explicada extensamente en Ramalho (2003) y Romero (2005). Los M-Files (archivos en MATLAB) que aquí se presentan, están orientados al uso computacional de éstos métodos.

Tabla 4. Ensayos DBO

\begin{tabular}{|c|c|}
\hline $\mathrm{T}$ (días) & $\mathrm{Y}(\mathrm{mg} / \mathrm{l}$ de $\mathrm{DBO})$ \\
\hline 1 & 9.2 \\
\hline 2 & 15.9 \\
\hline 3 & 20.9 \\
\hline 4 & 24.4 \\
\hline 5 & 27.2 \\
\hline 6 & 29.1 \\
\hline 7 & 30.6 \\
\hline
\end{tabular}

Fuente: Ramalho (2003).

\section{PROGRAMAS MATLAB}

\section{Arrhenius}

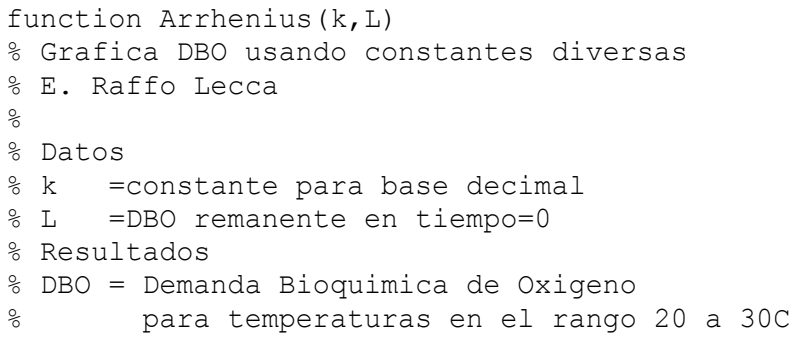

\section{Método mínimos cuadrados}

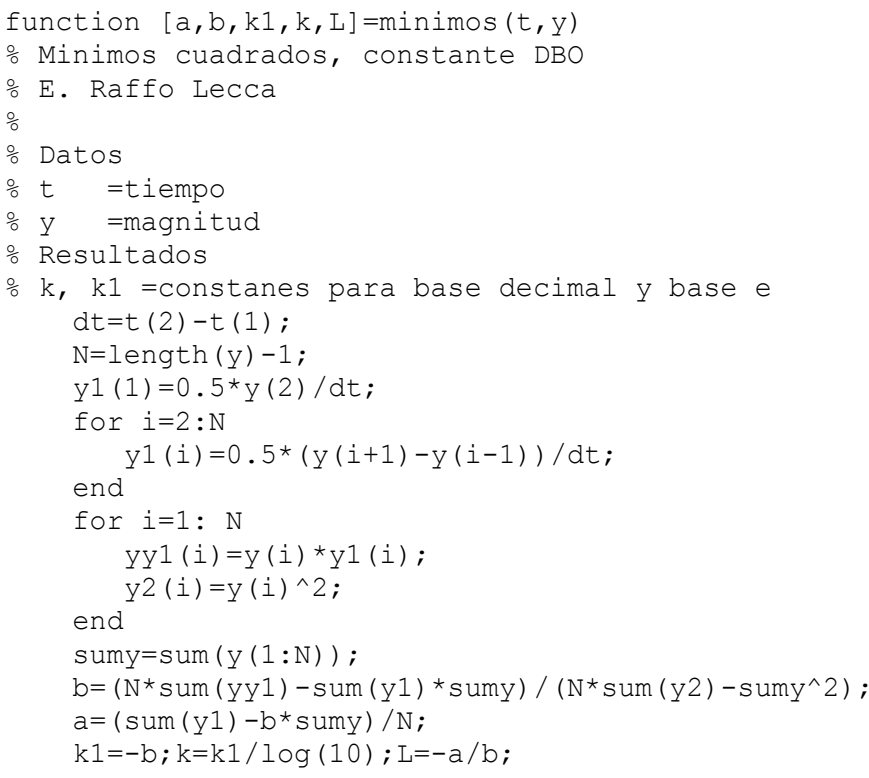

\section{Método de Thomas}

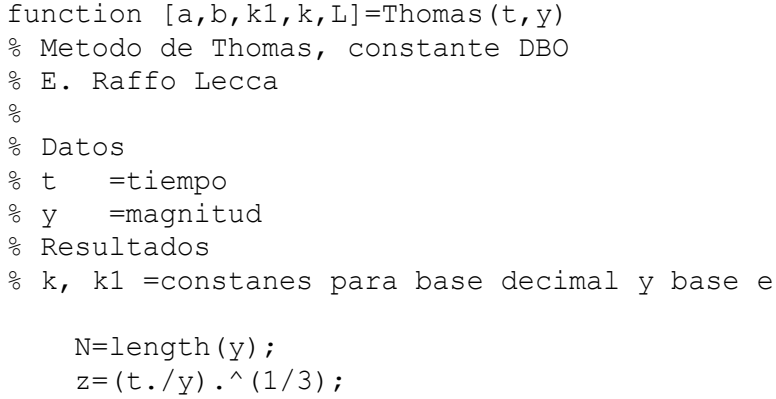




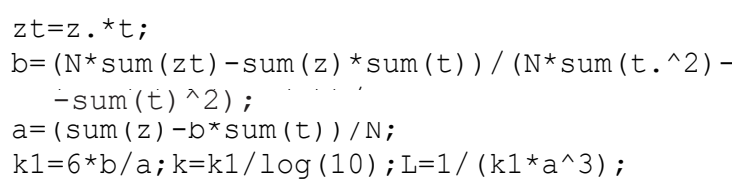

\section{Moore}

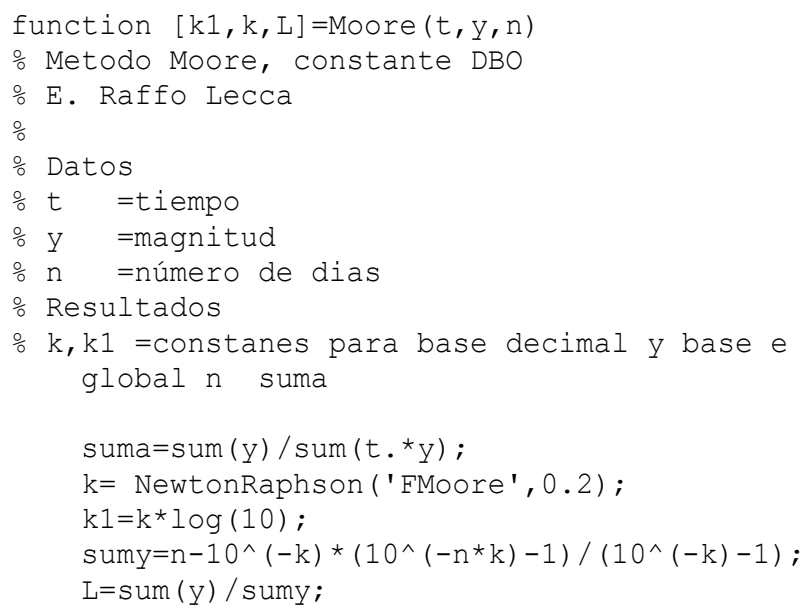

\section{NewtonRaphson}

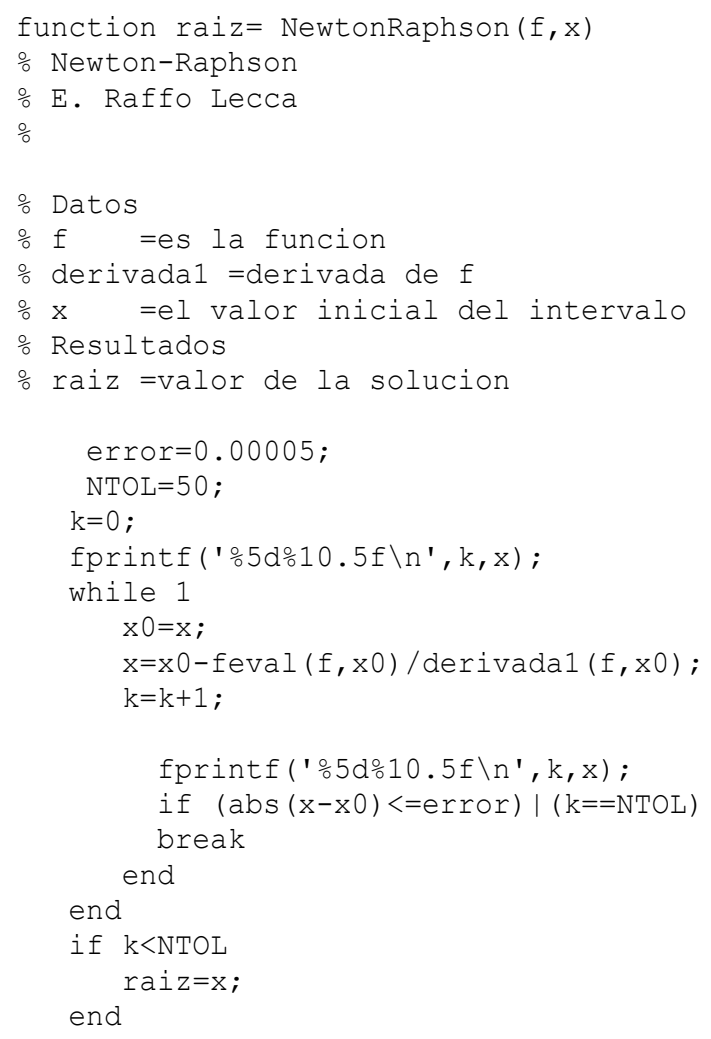

\section{Derivada1}

\footnotetext{
function $y=$ derivadal $(f, x)$

o Central difference approximations

o first derivate
}

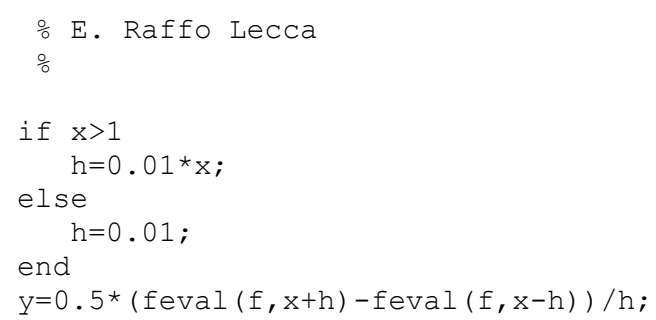

\section{FMoore}

function $\mathrm{p}=$ FMoore $(\mathrm{k})$

- Tabla Moore

: E. Raffo Lecca

Datos

\% $\mathrm{k} \quad$ constante

global n suma

sumy $=\mathrm{n}-10^{\wedge}(-\mathrm{k}) *\left(10^{\wedge}\left(-\mathrm{n}^{*} \mathrm{k}\right)-1\right) /\left(10^{\wedge}(-\mathrm{k})-1\right)$;

$\mathrm{I}=1: \mathrm{n}$;

sumty $=\operatorname{sum}(I)-\operatorname{sum}(I \cdot * 10 \cdot \wedge(-I * k))$;

$\mathrm{p}=$ sumy $/$ sumty - suma;

\section{CONCLUSIONES}

1. La investigación hidrológica es útil en cuanto que nos permite entender mejor el mundo en el que vivimos La vida está intrínsecamente relacionada con el agua.

2. El agua subterránea constituye una fracción importante de la masa de agua presente en los continentes.

3. Los humedales son zonas en las que el agua es el principal factor que controla el medio y la vida vegetal y animal relacionada con él.

4. La eutrofización produce de manera general un aumento de la biomasa y un empobrecimiento de la diversidad. En ecosistemas acuáticos, con la eutrofización empiezan a proliferar algas unicelulares, en general algas verdes.

5. A mayor cantidad de materia orgánica contenida en una muestra de agua, más cantidad de oxígeno necesitan los microorganismos para oxidarla o degradarla.

6. La Demanda Bioquímica de Oxígeno (DBO) se usa como una medida de la cantidad de oxígeno requerido para oxidación de la materia orgánica biodegradable, presente en la muestra de agua, como resultado de la acción de oxidación aerobia. 


\section{REFERENCIAS BIBLIOGRÁFICAS}

[1] Agua subterránea. http://es.wikipedia.org/wiki/ Agua_subterránea, visitado el 1 de septiembre de 2013.

[2] Acuíferos (2008). http://geografia.laguia2000. com/hidrografia/acuiferos, visitado el 1 de septiembre de 2013.

[3] Departamento de Sanidad del Estado de Nueva York (2012). Manual de Tratamiento de Aguas. México DF: México, LIMUSA, S.A. de C.V.

[4] Ecología verde. http://www.ecologiaverde.com/ eutrofizacion/, visitado el 1 de Septiembre de 2013.

[5] Eutrofización. http://es.wikipedia.org/wiki/ Eutrofización, visitado el 1 de septiembre de 2013.

[6] Kadlec, R., S. Wallace (2009). Treatment Wetlands. Boca Raton, FL: USA, CRC Press. Taylor and Francis Group, Second Edition.
[7] La Convención de Ramsar. http://www.ramsar.org/cda/es/ramsar-home/ main/ramsar/1-4000-2, visitado el 1 de Septiembre de 2013.

[8] Masters, G., W. Ela (2008). Introducción a la Ingeniería Medioambiental. Madrid, España: Pearson Prentice Hall, Tercera edición.

[9] Metcalf \& Eddy Eddy (1977). Quality Engineering Waterwater. USA.

[10] Raffo Lecca, E. (2013). Tratado del Agua y la Legislación Peruana. Lima, Perú: Industrial Data

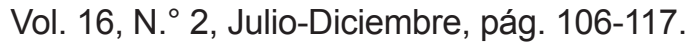

[11] Ramalho, R. (2003). Tratamiento de Aguas Residuales. Barcelona: España, Editorial Reverté, S.A.

[12] Romero Rojas, J. (2005). Lagunas de Estabilización de Aguas Residuales. Bogotá: Colombia, Editorial Escuela Colombiana de Ingeniería. 